\title{
Study on the Influence of China's Fiscal Policy on the Urban and Rural Income Gap
}

\author{
PENG Li ${ }^{1}$ and YANG Qingxian ${ }^{1 *}$
}

\author{
'211 Huimin Road, Wenjiang District, Chengdu City, Sichuan Province, China \\ 1140634457@qq.com
}

\begin{abstract}
Fiscal policy is usually a common means to narrow the income gap between urban and rural residents in China.Therefore, this paper uses multiple linear regression to choose the seven popular measures of fiscal policy to explore how it will affect on the urban and rural income gap.The conclusion concluded that the tax income level, education, social security and employment, urban and urban-rural community construction expenditure and urban-rural income ratio have the greatest impact on education; the positive relationship between finance supporting agriculture, medical and health expenditure and urban-rural income ratio, and the medical and health influence is more than all other variables.It also put forward three suggestions on strengthening investment in education, changing the policy tilt of government medical and health expenditure, and improving the expenditure structure of finance supporting agriculture, so as to provide some policy suggestions for narrowing the gap between urban and rural income in the future.
\end{abstract}

Keywords: fiscal policy, urban-rural income ratio, multiple linear regression, unit root and co-integration inspection

\section{INTRODUCTION}

In recent years, China's rapid economic development has emerged and become one of the second largest economy in the world. However, China, like other developing economies, is facing the problem of income imbalance. The income gap between urban and rural areas is also expanding due to the long-term urban-rural dual economic structure ${ }^{[1]}$, The widening income gap between urban and rural areas has become the focus of social attention. The report to the 19th National Congress of the CPC also made it clear about narrowing the gap between urban and rural areas, showing that adjusting the gap in income distribution and promoting integrated urban-rural development are also the long-term goals and policy hot spots of our country ${ }^{[2]}$. As a common tool used by countries to adjust the income gap, it is of certain practical significance and value to study how fiscal policy affects the urban and rural income gap.

There are many domestic studies on how fiscal policy affects the urban and rural income gap, most of which focus on the separate role of fiscal expenditure and taxation.Chen Xiaokun and Feng Shijie conducted empirical research on the panel data from 31 provinces, believing that the income gap between urban and rural residents will continue to narrow over time, and the structure of fiscal expenditure is an important influencing factor ${ }^{[3]}$; Zhu Deyun and Gao Yanyu specifically analyzed the impact of local government fiscal expenditure on the 2007-urban and rural income gap in 2018, and put forward policy suggestions from six aspects ${ }^{[4]}$; Many scholars also choose the influence of financial agriculture, education expenditure and social security expenditure on the income gap between urban and rural areas ${ }^{[5-8]}$. In view of the tax level, Zhang Weihang and Huang Ruting used panel data to study the relationship between the tax structure and the income gap between urban and rural residents, believing that expanding the proportion of income tax, while reducing the proportion of circulation tax, will help to improve the income gap between urban and rural areas ${ }^{[9]}$; Wen Guirong used the V AR and E CM models to measure the difference between the impact of the total national tax revenue and each part of the tax revenue on the urban and rural income gap, respectively ${ }^{[10]}$. Based on the research of many scholars, this paper will select the panel data from 2000-2019 to comprehensively analyze the impact of fiscal expenditure and tax on the income gap between urban and rural areas, in order to supplement the existing studies and make corresponding policy recommendations based on the research results. 


\section{RESEARCH METHOD AND DATA SOURCES}

\subsection{Model construction}

This paper mainly studies the impact of fiscal expenditure and tax on urban and rural income gap, and the model of a variable affected by multiple variables is multiple linear regression, so the urban and rural income gap as dependent variable, fiscal tax level and large proportion of total fiscal expenditure, financial agriculture, education expenditure, social security and employment expenditure, urban and rural community affairs expenditure and medical and health expenditure scale as independent variables, and establish the following multiple regression equation: $Y X_{1} \sim X_{6}$

$$
\begin{array}{r}
Y=\beta_{0}+\beta_{1} X_{1}+\beta_{2} X_{2}+\beta_{3} X_{3}+\beta_{4} X_{4}+\beta_{5} X_{5}+\beta_{6} X_{6}+\mu \\
\beta_{i}(i=0,1,2,3,4,5,6) \text { For the pending parameters; for }
\end{array}
$$
the random error term $\mu$

The measure of urban-rural income gap chooses the urban-rural income ratio commonly used in the academic community:

Per capita income ratio of urban and rural residents $=$ The per capita disposable income of urban residents Per capita net income of rural residents

The measure of fiscal tax level is indicated by the proportion of tax revenue in GDP, and the other five types of fiscal expenditure is represented by the total expenditure than the total fiscal expenditure.

\section{2 data sources}

The original data of urban and rural residents' income, tax and financial expenditure used in the Institute are all derived from the China Statistical Yearbook from 20092020

\section{THE CURRENT GAP OF INCOME BETWEEN URBAN AND RURAL RESIDENTS IN CHINA}

By collecting the per capita income of urban and rural residents from 2000 to 2019 , it can be seen from Table 1 that the income gap between urban and rural residents in China is very large. In 2010, the per capita disposable income of urban residents is nearly three times that of rural residents, which is largely due to our country to catch up with the economic industrialization, leading to the emergence of urban and rural dual economic structure. This phenomenon will not only hinder the highquality development of China's economy, but also affect social equity, and then lead to some social and political problems.
Table 1 Income ratio between urban and rural residents

\begin{tabular}{|c|c|c|c|}
\hline & $\begin{array}{c}\text { Urban } \\
\text { residents per } \\
\text { capita } \\
\text { disposable } \\
\text { income }\end{array}$ & $\begin{array}{c}\text { Country } \\
\text { dweller } \\
\text { Per capita } \\
\text { net income }\end{array}$ & $\begin{array}{l}\text { town and } \\
\text { country } \\
\text { Income } \\
\text { than }\end{array}$ \\
\hline In 2000, & 6280.0 & 2253.4 & 2.79 \\
\hline In 2001, & 6859.6 & 2366.4 & 2.90 \\
\hline In 2002, & 7702.8 & 2475.6 & 3.11 \\
\hline In 2003, & 8472.2 & 2622.2 & 3.23 \\
\hline In 2004, & 9421.6 & 2936.4 & 3.21 \\
\hline In 2005, & 10493.0 & 3254.9 & 3.22 \\
\hline In 2006, & 11759.5 & 3587.0 & 3.28 \\
\hline In 2007, & 13785.8 & 4140.4 & 3.33 \\
\hline In 2008, & 15780.8 & 4760.6 & 3.31 \\
\hline In 2009, & 17174.7 & 5153.2 & 3.33 \\
\hline In 2010, & 18779.1 & 6272.4 & 2.99 \\
\hline In 2011, & 21426.9 & 7393.9 & 2.90 \\
\hline In 2012, & 24126.7 & 8389.3 & 2.88 \\
\hline In 2013, & 26467.0 & 9429.6 & 2.81 \\
\hline In 2014, & 28843.9 & 10488.9 & 2.75 \\
\hline In 2015, & 31194.8 & 11421.7 & 2.73 \\
\hline In 2016, & 33616.2 & 12363.4 & 2.72 \\
\hline In 2017, & 36396.2 & 13432.4 & 2.71 \\
\hline In 2018, & 39250.8 & 14617.0 & 2.69 \\
\hline In 2019, & 42358.8 & 16020.7 & 2.64 \\
\hline $\begin{array}{c}\text { average } \\
\text { value }\end{array}$ & 20509.5 & 7169.0 & 2.98 \\
\hline
\end{tabular}
from 2010 to 2019

Note: The original data are obtained from the China Statistical Yearbook, 1999-2020

China's urban-rural income ratio has experienced three stages in nearly 20 years, from 2000 to 2003 , it expanded rapidly; 2003 to 2009 slowly expanded and peaked in 20093; 2009 from 2009 to 2019.This is mainly due to that in recent years, the government has taken many active fiscal policies to narrow the income gap between urban and rural areas, such as the abolition of farmers 'tax, increasing infrastructure construction and other measures, in order to improve farmers' income and improve their quality of life.Figure 1 can also see that these policies have achieved initial results, and the ratio of urban and rural residents falling from 2 in 2010 to 2 in 2019. However, compared with other developed countries, the income gap between urban and rural residents is still very large. By the beginning of the 2000s, the disposable income of the US agricultural population 
was 1.17 times that of the non-agricultural population; Japan had succeeded in separating urban and rural income in 1972, and the ratio of urban and rural income has basically fluctuated between 0.86 and 0.97 ; South Korea has basically decreased to about 3\% from 2005.99.64 ${ }^{[11]} .98 .64$. However, China's current urbanrural income ratio is 2 , and the lowest is 2 , so there is still a long way to go to truly break the urban-rural income gap.

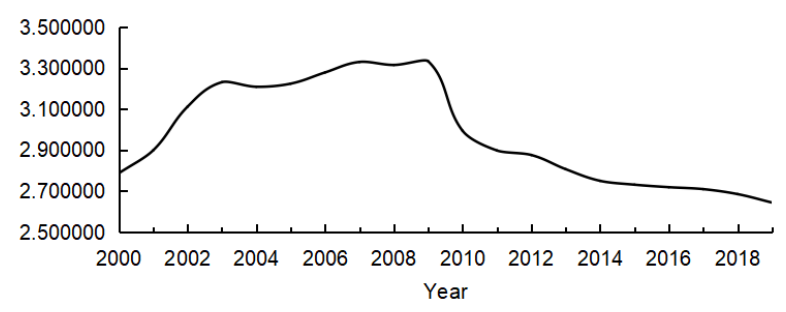

Figure 1 Income ratio between urban and rural residents from 2010 to 2019

\section{THEORETICAL ANALYSIS ON THE INFLUENCE OF FISCAL POLICY ON URBAN-RURAL INCOME GAP}

\section{1 theory evidence}

Fiscal policy is the tax and government expenditure conducted by the state to regulate the macro economy.According to Keynesian economics, the government can influence total demand by changing taxes, government spending, and thus affect national income. The change of fiscal policy is one of the main means by which the country relies to macro-control a country's economy. Due to the existence of the multiplier effect, both the tax reduction and fee reduction and the increase of government expenditure can be reflected in the national income through the multiplier effect, which is one of the most direct and efficient ways to regulate the national income ${ }^{[12]}$.

In his Theory of Public Property, Musgrave divided his government functions into three types: stabilizing the economy, income distribution, and redistribution.Under the requirements of market economy, the balance of factor expenditure and income, so equivalent exchange can promote fair economic realization; social equity is social intervention to maintain income gap in the acceptable range of various social class. This requires the government to intervene in the economy by administrative means to achieve social equity, but the absolute average is different concepts of social fairness, or even a deviation, so income fairness rather than average income is realized through financial means. Therefore, the government adopts the finance to adjust the income distribution.If the distribution belongs to the market, the finance cannot replace its position, give play to the role of tax revenue in regulating income, and standardize wage payment.In addition, government transfer payments can maintain the basic living standards of low income to a certain extent, and need supporting social security, relief expenses and subsidies ${ }^{[13]}$.

\section{2 influencing mechanism}

Fiscal policy usually affects the urban and rural income gap through fiscal expenditure and taxation (as shown in Figure 2).Taxation plays its role in regulating income gap in two aspects: on the one hand, reducing income source and reducing personal disposable income, and on reducing the actual purchasing power of personal disposable income. The tax policy adopted in China to narrow the income gap between urban and rural areas is usually to increase the tax on the rich and reduce the tax of the poor.For example, China's policy of abolishing farmers' tax has greatly increased rural residents' income to a large extent.

Expanding fiscal spending can encourage social consumption and increase the social purchasing capacity.Through investment in infrastructure and agriculture, the income can be increased and the income gap between urban and rural residents can be narrowed.Education, social security and employment, and health care are usually important factors affecting the urban and rural income gap ${ }^{[14]}$, In addition, these kinds of expenditures account for a relatively large proportion in China's fiscal expenditure, so they will have an impact on narrowing the urban-rural income gap to a certain extent.

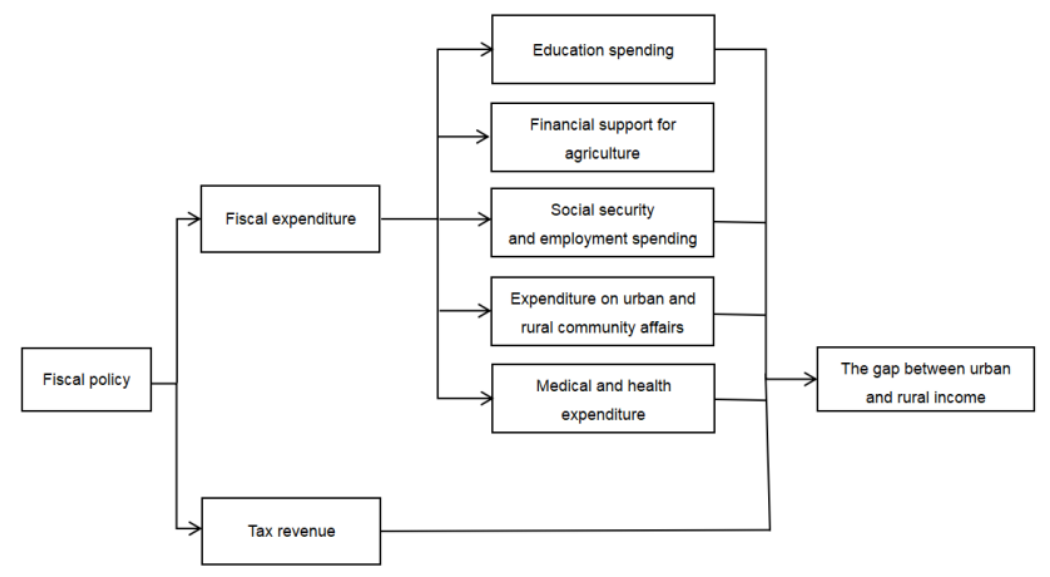


Figure 2 The impact path of fiscal policy on the urban and rural income gap

\section{EMPIRICAL ANALYSIS OF THE IMPACT OF FISCAL POLICY ON THE URBAN AND RURAL INCOME GAP}

\subsection{Unit root test}

Before the correlation analysis, the stationarity of each variable is tested to avoid the pseudo-regression phenomenon caused a long time span. ADF test fory, X1, $\mathrm{X} 2, \mathrm{X} 3, \mathrm{X} 4, \mathrm{X} 5$ and X6, first-order difference treatment, and then A DF test. The results are as follows:

Table 2 Unit of root test results

\begin{tabular}{|c|c|c|c|c|c|}
\hline variable & $\begin{array}{c}\text { ADF } \\
\text { statistics }\end{array}$ & $\begin{array}{c}1 \% \\
\text { critical } \\
\text { value }\end{array}$ & $\begin{array}{c}5 \% \\
\text { critical } \\
\text { value }\end{array}$ & $\begin{array}{c}10 \% \\
\text { critical } \\
\text { value }\end{array}$ & $\begin{array}{c}\text { Smooth- } \\
\text { ness }\end{array}$ \\
\hline$y$ & -0.587 & -3.750 & -3.000 & -2.630 & Unsmooth \\
\hline $\mathrm{X} 1$ & -2.721 & -3.750 & -3.000 & -2.630 & steady \\
\hline$x 2$ & -1.991 & -3.750 & -3.000 & -2.630 & Unsmooth \\
\hline X3 & -1.069 & -3.750 & -3.000 & -2.630 & Unsmooth \\
\hline$x 4$ & -1.652 & -3.750 & -3.000 & -2.630 & Unsmooth \\
\hline$\times 5$ & -0.282 & -3.750 & -3.000 & -2.630 & Unsmooth \\
\hline$x 6$ & -0.341 & -3.750 & -3.000 & -2.630 & Unsmooth \\
\hline $\mathrm{D}(\mathrm{y})$ & -2.739 & -3.750 & -3.000 & -2.630 & steady \\
\hline$D(X 2)$ & -3.753 & -3.750 & -3.000 & -2.630 & steady \\
\hline $\mathrm{D}(\mathrm{X} 3)$ & -4.737 & -3.750 & -3.000 & -2.630 & steady \\
\hline$D(X 4)$ & -4.361 & -3.750 & -3.000 & -2.630 & steady \\
\hline$D(X 5)$ & -4.467 & -3.750 & -3.000 & -2.630 & steady \\
\hline$D(X 6)$ & -3.699 & -3.750 & -3.000 & -2.630 & steady \\
\hline
\end{tabular}

Note: Data are obtained from the S TATA software.

As can be seen from Table 2, X1 zero order is stable, and $\mathrm{y}, \mathrm{X} 2, \mathrm{X} 3, \mathrm{X} 4, \mathrm{X} 5$, and $\mathrm{X} 6$ are all stable in first order difference, thus indicating that their first order difference sequence is stable, that is, first order single consolidation, and the original sequence can be co-rectified by the test.

\subsection{Co-integration test}

The method of the coconsolidation test mainly includes the E-G two-step method and the Johensen test, but the $\mathrm{E} G$ coconsolidation test is only suitable for the analysis of two variables. Since the coconsolidation relationship between multiple variables is studied, the Johensen method is finally chosen to see whether there is a coconsolidation relationship between the variables.

(1) The V AR model was established and the optimal order was established
Table 3 Significance of the V AR models at different lag orders

\begin{tabular}{ccccccc}
\hline Lag & LL & LR & FPE & AIC & HQIC & SBIC \\
\hline 1 & 504.56 & 242.54 & $2.1 \mathrm{e}-33$ & -56.07 & -55.93 & -53.36 \\
& & $*$ & & & & \\
2 & $/$ & $/$ & $0^{*}$ & $/$ & $/$ & $/$ \\
3 & 3938.64 & $/$ & $/$ & -478.33 & -478.05 & -472.92 \\
4 & 3958.02 & 38.77 & $/$ & $-480.75^{*}$ & $-480.48^{*}$ & - \\
& & & & & & $475.345^{*}$
\end{tabular}

Note: * Represents the significance of the index, * the more, the greater the significance; the data is derived from S TATA software.

Table 3 shows that the highest significance level occurs when the V AR model lag order is 4 , so that the optimal order of the V AR model is 4 .

(2) Johensen test

Table 4 Results of the Johensen test

\begin{tabular}{ccccc}
\hline rank & parms & eigenvalue & $\begin{array}{c}\text { Trace } \\
\text { statistic }\end{array}$ & $\begin{array}{c}5 \% \\
\text { critical } \\
\text { value }\end{array}$ \\
\hline 0 & 14 & $/$ & 190.1317 & 136.61 \\
1 & 27 & 0.98053 & 115.2962 & 104.94 \\
2 & 38 & 0.88525 & $74.1613^{*}$ & 77.74 \\
3 & 47 & 0.72956 & 49.3150 & 54.64 \\
4 & 54 & 0.67842 & 27.7592 & 34.55 \\
5 & 59 & 0.55757 & 12.2652 & 18.17 \\
6 & 62 & 0.47397 & 0.0597 & 3.74 \\
7 & 63 & 0.00314 & $/$ & $/$ \\
\hline
\end{tabular}

Note: * Represents reject null hypothesis at 5\% significant level, its line represents number of coconsolidation; data is from STATA software.

From the above test results, there are long-term cointegration relations between $\mathrm{y}, \mathrm{X} 1, \mathrm{X} 2, \mathrm{X} 3, \mathrm{X} 4, \mathrm{X} 5$, and $\mathrm{X} 6$, and there are two coconsolidation equations.

\subsection{Return results}

Through the above analysis, there is a coconsolidation relationship between the variables. Next, the regression analysis is conducted through the error correction model (E CM). According to the relationship between the cocorrection and the error correction model, the corresponding vector error correction model (V ECM) can be obtained. The regression results corrected by the model are as follows: 


$$
\begin{gathered}
\mathrm{Y}=-1.626126-7.11022 \mathrm{X} 1+5.142947 \mathrm{X} 2 \\
-13.71703 \mathrm{X} 3-12.32039 \mathrm{X} 4 \\
-9.206521 \mathrm{X} 5+43.06521 \mathrm{X} 6
\end{gathered}
$$

Table 5 Error correction results

\begin{tabular}{ccccc}
\hline Var & Coef & Std.error & Z & $P$ \\
\hline X1 & -7.11022 & 1.834971 & -3.87 & 0.000 \\
X2 & 5.142947 & 1.925555 & 2.67 & 0.008 \\
X3 & -13.71703 & 2.649219 & -5.18 & 0.000 \\
X4 & -12.32039 & 1.96713 & -6.26 & 0.000 \\
X5 & -9.206521 & 2.122364 & -4.34 & 0.000 \\
X6 & 43.06734 & 3.489211 & 12.34 & 0.000 \\
C & -1.626126 & $/$ & $/$ & $/$ \\
\hline
\end{tabular}

Note: Data are obtained from the S TATA software.

From the above analysis results, it can be seen that the fiscal tax level is negatively related with the urban-rural income ratio.In other words, for every unit increase in tax revenue level, the urban-rural revenue ratio will decrease by 7.11022. This shows that China's adjustment of the tax structure has achieved initial results in recent years, by increasing the income tax and then narrowing the income gap for some high-income people.

Fiscal support for agriculture is positively related to the income ratio between urban and rural areas.This shows that although China's investment in agriculture is increasing, it instead expands the income gap between urban and rural areas. The reason may be that the unreasonable expenditure structure, which has not played an effect on helping farmers increase their income. The dual structure between urban and rural areas is prominent and the gap between urban and rural areas is constantly expanding.

Education expenditure is negatively associated with the urban-rural income ratio.In other words, for every unit of education expenditure, the urban-rural income ratio will shrink by 13.71703 units, indicating that education plays a prominent role in narrowing the income gap between urban and rural areas. The rural child base is large, but at the same time, the education level is relatively backward compared with the city. In recent years, in order to ensure education fairness, China has increased the investment in rural education, so that many migrant workers' children can achieve their personal goals through education, help their whole families improve the quality of life, and narrow the income gap between urban and rural areas.

Social security and employment expenditure are negatively associated with the urban-rural income ratio.In other words, for each unit increase in social security and employment investment, the urban-rural income ratio decreased by 12.32039 , which shows that increasing investment in social security and employment can play a role in narrowing the income gap between urban and rural areas.China has a large number of farmers, and most of them are engaged in labor farming at home. The annual family income is very small, which can not be compared with urban and rural residents at all.However, with the development of China's economy, the social security and employment security for many migrant farmers, increase their enthusiasm to go out for employment, but also improve the wage income of their families, and thus can narrow the income gap between urban and rural areas.

The expenditure on urban and rural community construction is negatively related to the urban and rural income ratio, which means that now the increasing fiscal expenditure on urban and rural community construction now can narrow the income gap between urban and rural areas.In order to narrow the income gap between urban and rural areas and make the living standards of farmers be improved simultaneously, China's investment in the construction of rural communities is also increasing.By changing the overall style of the countryside, improving the quality of life of the residents, so that they have greater confidence to strive to change the family situation, so as to constantly close to urbanization.

Medical and health expenditure is positively related to the urban and rural income ratio, which shows that although China increases the medical and health expenditure, the gap between urban and rural areas has not been improved, but keeps increasing, which is also caused by the unreasonable expenditure structure. At present, the rural health conditions are poor, one is because of the broad rural area, no problem to meet the basic medical needs of each region, but it is still a long way to go to reach the same level in the city; second, many highly qualified doctors want to work in big cities, which leads to the uneven rural medical team.However, it can be seen from the above research results that medical treatment and health care have the most prominent impact on the urban and rural income gap in China, so China should pay attention to the problem of rural medical treatment.

\section{CONCLUSIONS AND SUGGESTIONS}

On the basis of establishing a multiple linear regression model, this paper analyzes how the Chinese fiscal policy affected the income gap between urban and rural areas from 2000 to 2019, and draws the following conclusions:

(1) Tax income level, education, social security and employment, and urban and rural community construction expenditure are negatively related to the urban and rural income ratio, and the impact of education is the greatest.This shows that increasing taxes, 
education, social security and employment, and urban and rural community construction can narrow the income gap between urban and rural residents.

(2) The positive relationship between financial agriculture and medical and health expenditure and the income ratio between urban and rural areas, and the impact degree of medical and health care exceeds all other variables. This shows that in recent years, increasing financial support and medical and health expenditure has not narrowed the income gap between urban and rural areas, but also intensified the income gap between urban and rural residents.

According to the above analysis and conclusions, in order to further narrow the urban and rural income gap, the following three suggestions are put forward for China's current financial policy:

\section{(1) Increased investment in education}

Through empirical analysis, it can be found that among the four factors that narrow the urban and rural income gap, education is greater. Therefore, increasing the investment in education must be the only way to narrow the urban and rural income gap.In addition, educational fairness is mentioned in the report to the 19th CPC National Congress, which shows that it has been deeply concerned by the country. Therefore, China needs to further increase its investment in education, especially as in some poor areas, to fundamentally solve the problem of education fairness in urban and rural areas.In addition, the government should also provide more and larger platforms for farmers to have the opportunity to learn more deeply, so as to improve their cultural quality and technical ability, and help them to be more competitive in large cities and business activities, so as to narrow the income gap between urban and rural residents.

(2) Change the policy tilt of government medical and health expenditure

Our current medical and health investment is very large, but intensified the gap between urban and rural areas, the reason and policy investment tilt is not reasonable, our long-term health funds led to urban health labor gap between urban and rural income gap, however, according to this study, medical, health investment has the biggest impact on urban and rural income gap, so change the current health spending policy tilt is not slow.Therefore, the government should increase the investment in medical and health care in rural areas to break the "urban and rural dual structure" of public health services, narrow the gap between urban and rural healthy labor capital, and then narrow the gap between rich and poor between urban and rural areas.

(3) Improve the structure of fiscal spending for supporting agriculture

Increasing investment in irrigation and water conservancy affairs can promote urban-rural integration and narrow the income gap between urban and rural areas.However, at present, China's country has a lot of total investment in agriculture, but the income gap between urban and rural areas has not improved, the reason is that the structure of agricultural funds is unreasonable.China's rural areas are large, and the agricultural situation of each region is not the same. Therefore, each province should innovate their own agricultural system according to the agricultural shortcomings of the region.Second, a variety of ways to support agriculture, such as finance, education, general transfer payment, etc., and to achieve through financial supporting agriculture to reduce the effect of fiscal supporting agriculture, should increase investment in rural infrastructure construction, only let residents' life become more convenient, can have conditions and motivation to increase income production activities

\section{REFERENCES}

[1] Pan Linwei, Wu Yaling.Empirical Study on Financial Development, Financial Policy and urban-rural income gap based on partial least squares regression [J].Southwest Finance, 2019 (02): 25-32.

[2] Gao Xiaoyue, Wang Yanxia.Empirical Analysis of implementing fiscal policies to narrow the income distribution gap between Urban and Rural Residents [J].China Agricultural Accounting, 2020 (12): 7274.

[3] Chen Xiaokun, Feng Shijie.The impact of fiscal expenditure structure on the income gap between urban and rural residents — is based on a panel quantile regression model of 31 provinces and cities [J].Journal of Henan University of Science and Technology, 2021,41 (03): 1-8 + 41 .

[4] Zhu Deyun, Gao Yan domain.Study on the Impact of Local Financial Expenditure Structure on the Income Gap between Urban and Rural Residents - Empirical Study based on provincial panel data containing virtual variables [J].Fiscal Science, 2020 (09): 98-113.

[5], Hua Yongchun.The impact of fiscal agricultural expenditure on urban and rural income gap — is based on Chinese provincial panel data [J].China Collective Economy, 2020 (31): 4-6.

[6] Song Yingjie, Qu Jingya.Effect of fiscal vocational education expenditure on the urban and rural income gap [J].Public Finance Research, 2018 (03): 27-38.

[7] Liang Juan.Effects of Financial Social Security expenditure on urban and rural income gap empirical analysis based on panel data from five northwest provinces [J].Modern Trade Industry, 2017 (27): 7-8. 
[8] Wang Xuan, make public.Empirical test of the impact of financial agriculture and social security expenditure on the income gap between urban and rural residents $[\mathrm{J}]$.Statistics and Decision-making, 2019,35 (06): 127-130.

[9] Zhang Weihang, Huang Ruting.Effect of tax structure on urban-rural income gap [J].Journal of Xi'an Jiaotong University (Social Sciences Edition), 2018,38 (02): 86-92.

[10] Wen Guirong.Empirical study of tax system affecting urban and rural income gap [J].Business Studies, 2017,24 (04): 94-103.

[11] Huang Kun, Dong Li.Experience and enlightenment of narrowing the income gap between Urban and Rural Residents abroad [J].Modern Economic Information, 2011 (24): 297-298.

[12] Zhu Gaozhou.Impact of proactive fiscal policy on China's inflation rate [J].Cooperative Economy and Technology, 2020 (16): 182-183.

[13] Lee Pepe.Study on Financial Countermeasures to Close the Income gap between Urban and Rural Residents in Shandong Province [D].Shandong University of Finance and Economics, 2015.

[14] Shan Zhang.Study on Fiscal Policy of Urban and Rural Residents in Shanxi Province [D].Shanxi University of Finance and Economics, 2017. 